\title{
CONTRA-TIEMPOS ANTROPOLOGICOS*
}

\section{Enrique Luque Baena}

Universidad Autónoma de Madrid

La guardia civil del Danubio, los legionarios de Bosnia; son expresiones contemporáneas que a algunos nos dejan alucinados por sus cruces semánticos.

Resulta innegable y al propio tiempo alentador el crecimiento que la antropología ha conocido en nuestro país en apenas poco más de dos décadas. Dentro y fuera de los ámbitos universitarios, pero especialmente en estos últimos. Rara va siendo ya la universidad donde la disciplina no está presente en mayor o menor medida. La puesta en marcha de planes de estudio y licenciaturas contribuirá, sin duda, a incrementar un ritmo casi inimaginable a principios de los setenta. Algo que está encontrando eco también en el interés por la antropología por parte de los organismos autonómicos y otras entidades, hoy públicas y quién sabe si privadas o privatizadas mañana.

Ante un panorama que sólo parece que puedan enturbiar los vaivenes de la actual crisis económica, tal vez suene a aguafiestas - y este término, como veremos, tiene pleno sentido en algo a lo que luego me referiré- lo que quiero

* Este artículo representa una ligera revisión de parte de otro algo más amplio presentado en el VI Congreso de Antropología Española, Tenerife, septiembre de 1993.

1 El Pais, 23-5-1993. 
plantear aquí. Ahora bien, de nuestro país y de nuestra antropología quiero ocuparme más adelante. De momento intentaré plantear el problema en términos bastante más generales. $\mathrm{O}$, si se quiere, de una manera un tanto simplificadora y brutal. ¿Está preparada la antropología —epistemológica y heurísticamente- para abordar las realidades que nos circundan? ¿Nos hemos detenido siquiera a manifestar alguna zozobra al respecto? Me temo que, para muchos, el momento de las vacilaciones, si alguna vez lo hubo, ha quedado atrás y bien atrás. "Hablan en voz más alta (...) con el aplomo de quienes ignoran la duda», dice sarcásticamente de nosotros, los españoles, Jorge Luis Borges (1981:37).

Y otra pregunta: ¿entendemos qua antropólogos el mundo que nos ha tocado vivir? A veces tengo serias dudas. Imaginemos una reunión de sabios, como antes se decía, en la que, junto a teólogos, biólogos, físicos y filósofos, participa un antropólogo social. Tras cuatro días de debates sin ninguna intervención de este último, toma por fin la palabra para desvincularse de las preocupaciones de los demás, pobres mortales, y asegurar que su papel allí es el de observador objetivo de fenómenos de enfrentamientos y coaliciones. Los temas de fondo y la lógica de la argumentación parecen, pues, irrelevantes; simples formas de comportamiento verbal. Quien asegura que ese cuadro no es pura ficción es nada menos que Sir Karl R. Popper, que, además, tilda con justicia de marciano al antropólogo y duda, con razón, de que su pretendida objetividad tenga algo que ver con el quehacer científico (Popper, 1972: 106-109).

\section{LA HUIDA DEL PRESENTE Y LA NEGACION TEORICA DEL TIEMPO}

Exagerada o más o menos real, la anécdota ilustra cuál puede ser nuestra situación vista desde fuera. No creo, con todo, que el común de mis colegas —aquí y fuera de aquí- siga haciendo gala de ese détachement ingenuamente objetivista o positivista que ridiculiza el filósofo. Alguno debe quedar por acá y por acullá. Pero esos alardes en público hace años que dejaron de ser de buen tono.

Otros, en cambio, sí que siguen teniendo carta de naturaleza y gozando de predicamento. Confieso que la obra y el pensamiento de Claude Lévi-Strauss me producen sentimientos muy ambivalentes. Me imagino que como a cualquiera de mis colegas, aunque tal vez por motivos diferentes. Me seduce su prosa, me fascinan muchos de sus análisis, admiro y envidio la amplitud de sus gustos, intereses y conocimientos... y me irritan profundamente sus argucias dialécticas. Detesto, además, que no sólo fuera de los ámbitos antropológicos, sino en buena medida también dentro, $s u$ antropología se haya considerado y se siga considerando la antropología. Máxime cuando, como cabría esperar, sus actitudes éticas y estéticas permean, mal que le pese, su entera producción. Una obra - se ha dicho y repetido- que ha conocido notables cambios temáticos, pero que, a mi modo de ver, conjuga esa versatilidad con una inconmovible lealtad a ciertas profundas convicciones. Una de ellas parece ser, precisa- 
mente, su rechazo o incluso su repugnancia con respecto a la actualidad, a lo contemporáneo.

Así se manifestaba hace poco ante el importuno periodista que le acuciaba para que se pronunciara acerca de la tragedia de la antigua Yugoslavia:

«Puedo decirle que todas esas cosas ya han ocurrido en el pasado. ¿Y quiere que yo le hable de su importancia porque suceden durante mi corta existencia.

Usted también habla de nuestros días: advierta que son angustiosos sólo para nosotros. Todos los hombres han vivido períodos terribles a sus ojos (...) Nuestras angustias actuales se fundirán con las pasadas y las futuras.»

¿De qué se ocupa, pues, el antropólogo por antonomasia?

"Lo que me interesa de los hombres es el equivalente de las conchas (de los moluscos), es decir, las obras que ellos “segregan”. Tienen una belleza y un sentido totalmente independientes de los organismos que las fabrican.

Es necesario tener tiempo, es necesario consagrarse enteramente al hombre contemporáneo. Raymond Aron, amigo mío, lo hacía de manera espléndida. Yo hice una elección, la de interesarme por cosas muy lejanas en el espacio y en el tiempo» ${ }^{2}$.

De pasada: la referencia a Aron (¿la sociología?) recupera sin tapujos desde la antropología la vetusta y, al parecer, no superada división del trabajo entre las ciencias sociales. El aqui y el ahora, frente al alli y el entonces. Pero voy a detenerme en otro contraste íntimamente relacionado con éste. Lo ilustra muy bien Lévi-Strauss con su metáfora del molusco. Subraya el antropólogo cómo su interés por las conchas que esas formas de vida segregan deriva de que encierran verdades matemáticas. Tal vez, más pitagórico en esta ocasión que kantiano en muchas otras, debe menospreciar en todo caso al sujeto segregante - el hombre de carne y hueso unamuniano- y considerar científicamente irrelevantes sus angustias y tribulaciones del momento. Las matemáticas podemos considerarlas sub specie aeternitatis; las segundas, en cambio, aunque reiterativas, son pasajeras. Temporales, en suma.

Para mí, aquí está una de las claves del problema: el tiempo, la temporalidad. La renuncia a abordarlo con una mínima radicalidad y profundidad equivale a renunciar a entender qué terreno pisamos, por más que proclamemos que estudiamos e investigamos temas de actualidad.

El ejemplo del estructuralismo lévi-straussiano es, sin duda, un caso extremo. «Su estrategia - ha dicho uno de sus críticos- consiste en eliminar el

${ }^{2}$ Entrevista concedida a Ulderico Munzi, Corriere della SeralEl Mundo, 3-5-1993. 
Tiempo como una dimensión significativa, ya sea de la integración cultural o de la etnografía» (Fabian, 1983: 52). Pero, al fin y al cabo, se trata de una estrategia coherente con ese intento del antropólogo francés de estudiar verdades matemáticas; esto es, entidades desprovistas de tiempo. No, curiosamente, de espacio. Recordemos su preocupación por situar la etnografía de mitos o de fenómenos relacionados con el parentesco en lugares, no en tiempos concretos. Por eso mismo considera Lévi-Strauss garantía de que un hecho social total corresponda con la realidad el que sea abarcable "en una experiencia concreta»: una sociedad o un individuo localizado en el espacio $o$ en el tiempo. Por ejemplo, dice, Roma y Atenas (tiempo y espacio); pero también «el melanesio de tal o cual isla» (Lévi-Strauss, 1978: XXVI; cursiva, mía). No, por supuesto, el melanesio de tal o cual época. Una lástima para el desarrollo teórico de la antropología que quien podría haber contribuido al mismo como pocos haya optado por el escapismo a lugares lejanos o a tiempos que, más que remotos, parecen cristalizados o fosilizados.

El planteamiento de Lévi-Strauss supone, se ha dicho ya, la eliminación del tiempo y, por ello mismo, la incapacidad radical para entender el mundo contemporáneo. Pero, extremismos aparte, no es caso insólito. Ni dentro ni fuera de los lares antropológicos. En nuestros enfoques y esquemas, en los que están detrás de nuestras investigaciones por más inconsciente que se sea de ellos, sigue imperando el primado de la variable espacial. Por mucho que hagamos — va siendo ya costumbre - rituales proclamaciones en loor del tiempo, de la historia o del cambio social.

Una vez pasada la moda de los estudios de comunidad, su lugar lo han ocupado los de identidades regionales y/o nacionales, los de ciudades, fábricas, barrios, comarcas, etc. No dudo que en todos ellos - y algunos conozco bastante de cerca- está presente el factor tiempo, la dimensión histórica o cualquier otra expresión de lo cambiante y perecedero. En todo caso, bastante más de lo que estaba en la mayoría de aquellos estudios de pueblos, aldeas y villorrios. Pero la balanza sigue inclinándose a favor del espacio.

Va a ser realmente difícil que nos desembaracemos por completo de ciertas premisas del trabajo de campo congruas con las del funcionalismo. Premisas que suponían, precisamente, una repulsa consciente y deliberada del tiempo y una hipervaloración de lo espacial. De la isla melanesia o la tribu africana (mucho más difícil ya de fijar espacialmente) a la ciudad provinciana, el barrio o el centro sanitario, parece que continuamos buscando unidades de bordes delimitados por los que uno puede moverse. Mucho más aislables, en todo caso, espacial que temporalmente.

Lo paradójico del caso es que aquel rechazo casi programático del tiempo por parte del funcionalismo y de los primeros trabajos de campo sólidos estaba más que justificado en un cierto sentido. Se luchaba de ese modo contra una noción del tiempo - la evolucionista - que hoy nos parece impugnable también, aunque por razones muy diferentes. El tiempo de los evolucionistas era el tiempo universal y homogéneo, natural y, por ello, negación de la historia. 
Algo que Herbert Spencer dejó muy claro cuando afirmaba: «Hasta que no se tenga una verdadera teoría de la humanidad no podrá interpretarse la historia, y cuando se tenga (...) ya no se necesitará la historia» ${ }^{3}$. La revolución en la física de este siglo vendría a trastocar los cimientos de esa artificiosa oposición al reivindicar un concepto del tiempo que tiene que ver más con el de los historiadores que con el de Newton o Laplace (Prigogine, 1992 y 1993).

Nada tiene, por tanto, de extraño que el intento de eliminación del tiempo, funcionalista primero, estructuralista después, condujera a la paradoja que resaltó y trató de resolver con lucidez Sigfried F. Nadel. A saber, que la estructura social, es decir, el concepto privilegiado por uno y otro enfoque, fundamentalmente sincrónicos, no podía definirse — como algunos intentabanpor su permanencia, estabilidad o duración al margen del tiempo (Nadel, 1966: 196-206). Aunque, tal vez, otros fenómenos claramente espaciales no planteen esos problemas. Por ejemplo, el territorio, los límites y la extensión de nuestras unidades de observación. ¿O no es esto más que una ilusión?

Por las mismas fechas en que aparecían aquellas declaraciones del autor de Mitológicas en la prensa, otro diario, The Washington Post, recogía un agudo comentario a propósito de un estudio histórico sobre la extinta Yugoslavia. Su autora decía lo siguiente:

«Los Balcanes son un mundo invertido: la historia se mantiene mientras que la geografía cambia. Las invasiones vuelven a trazar el mapa de los Balcanes en pocas décadas, provocando nuevas invasiones. En la guerra actual de Yugoslavia, como en las guerras del pasado, los agresores buscan recuperar el momento de su mayor gloria. "Cada nación”, escribe Kaplan, "exige que sus fronteras reviertan a donde estaban en el momento exacto en el cual su imperio había alcanzado el zénit de la antigua expansión medieval" ${ }^{4}$.

Parafraseando la conocida frase de Lévi-Strauss a propósito del totemismo, cabría decir que la tragedia de los Balcanes no sólo es buena para sufrir, sino también para pensar. Aunque quizá el problema de muchos intelectuales estribe en que tratan de disociar artificiosamente sus funciones intelectivas del gozo o del sufrimiento. Operación cartesiana en la que uno corre el riesgo de no entender ni lo que le rodea ni las trascendentes cuestiones de las que dice ocuparse.

3 Citado por Burrow (1970: 198-199). Se trata de una carta de Spencer que he adaptado al estilo impersonal. Véase también Fabian (1983: 11 ss.).

4 Tina Rosenberg, comentario al libro de Robert D. Kaplan, Balkans Ghost: A Journey Through History, en The Guardian Weekly, 2-5-1993, p. 20. 


\section{EL PESO DEL TIEMPO}

Esa resistencia ante la temporalidad casa mal con lo que podría denominarse la obsesión por el tiempo del hombre contemporáneo. Lo ha señalado hace poco Marc Augé al referirse a la más rabiosa actualidad (1993: 36 ss.). Esta, a la que denomina surmodernité, viene a ser la otra cara de la postmodernidad y se caracteriza por el exceso. Ante todo, el exceso de tiempo, dada la superabundancia de acontecimientos con que nos bombardean los medios de comunicación. Pero también un exceso de espacio. Curiosamente, mientras el mundo se nos hace cada vez más pequeño, gracias a los viajes y a la perspectiva que dan los satélites artificiales, nuestros hogares se llenan de muchos espacios de los más remotos lugares del planeta por la vía de la televisión. Un mundo, como bien dice Augé, en el que vivimos pero que no hemos aprendido a mirar todavía. $\mathrm{Y}$, añado yo, que será muy difícil que lo logremos si seguimos aferrados a ciertos cimientos inconmovibles.

En todo caso, pienso que ese exceso de tiempo, que, como señala Augé, viene a desbordar el tiempo mismo, puede ser el final de un proceso que se inicia con lo que se suele denominar edad contemporánea. Un proceso aquél que ha supuesto el tributo que esa época ha pagado por ser diferente de los hombres salvajes o primitivos o de su propio pasado. Como dice Hans-Georg Gadamer, "la conciencia histórica que caracteriza al hombre contemporáneo es un privilegio, quizá incluso una carga, que, como tal, no ha sido impuesta a ninguna de las generaciones anteriores» (1993: 41).

Pero el mundo occidental ha conocido desde la edad moderna a la actualidad un importante cambio cualitativo en relación con el tiempo 5 . Primero la ética protestante, con los controles horarios que, de los monasterios, pasan a regular la vida del cristiano laico. El derroche de lo que se fragua ya como realidades intercambiables, esto es, del tiempo y del dinero, se convierte en moral y económicamente reprobable. Pero es la Revolución Industrial la que consagra la nueva forma de producción y dominación: «el cronómetro entra en el taller y se convierte, en palabras de Coriat, en un instrumento político de dominación sobre el trabajo» (Iglesias de Ussel, 1987: 120).

Pero nuestro tiempo inmediato es ya muy otro. La aceleración del ritmo del cambio social - señala Iglesias casi al final de su trabajo- provoca la obsolescencia del pasado y hace del reloj digital «el símbolo más elocuente de la nueva era». Y, recogiendo unas agudas palabras de Servan Schreiver, escribe: " "El reloj de esfera y agujas se parecía a todos los relojes de los siglos pasados. El tiempo gira en ellos como un caballo con correa alrededor de su domador. En esta circularidad de los minutos y las horas, la duración se enrosca sobre sí misma con el planeta y la galaxia. Como inmutable." Con el reloj digital por el contrario el tiempo, al cesar de girar, se pulveriza. Cada segundo empuja al

${ }^{5}$ En las líneas que siguen me baso, de forma muy resumida, en el excelente ensayo sobre este tema de Julio Iglesias de Ussel que aparece en la bibliografía. 
anterior a la nada y pone fin a la ilusión de un tiempo circular y repetitivo» (Iglesias de Ussel, 1987: 131 y 132).

\section{LA NEGACION PRACTICA DEL TIEMPO}

Quiero hacer una pausa para confesar en este punto que he sido no sólo usuario, sino también siervo, de esa aterradora máquina, el reloj digital, y que, desesperado, he vuelto de nuevo al dieciochesco reloj de esfera. Digo siervo porque nunca he abandonado del todo este último, y la combinación de ambos, unida probablemente a mi torpeza y a la baratura del ingenio, hacía que fuera tarea muy penosa compaginar el segundero de uno con ese vértigo de los segundos de otro. Uno de los dos marchaba mal y, al final, hacía que me preguntara para qué diablos me interesaba a mí saber qué segundo era cuando ya no era. He optado, en definitiva, por liberar mi mente del problema colocando la vieja ficción en mi muñeca.

Creo que algunos (que tal vez hayan superado con éxito la prueba del digital) llevan, en cambio, algo parecido a la esfera repetitiva en sus cabezas. Pondré tres ejemplos, algunos con nombres y apellidos. Los dos primeros suponen, al parecer, un intento de insertar temática antropológica en marcos de palpitante actualidad. El tercero se me antoja pura inmersión en la atemporalidad so capa de análisis antropológico de realidades históricas. Los tres representan, qué duda cabe, novedosos intentos de llevar la investigación fuera de campos más que trillados en la etnografía hispana de los sesenta y setenta (esto es, comunidades rurales más o menos abarcables y homogéneas o el mundo rural, en términos generales). Sin embargo, tratando de situarse en el tiempo, actual o pasado, se colocan —intencionadamente o no- fuera de él. Tal vez, porque en los tres casos se parta de una premisa cada vez más cuestionable y cuestionada: que lo inmanente, lo recurrente o lo incambiable es terreno más sólidamente científico que lo fugaz, lo cambiante o la sorprendente conjunción de lo conocido en diferentes épocas y contextos, pero en combinación difícilmente repetible.

El primero de esos ejemplos no es que sea anónimo precisamente. Lo que ocurre es que responde a una perspectiva muy extendida entre muy diversos profesionales de la pluma o de la palabra: periodistas, políticos y, por supuesto, científicos sociales, antropólogos incluidos. Me refiero al auge de los nacionalismos en los años que vivimos y a su presentación como un fenómeno cíclica o periódicamente recurrente. No voy a abordar aquí el tema en su enorme complejidad ${ }^{6}$.

${ }^{6}$ Llevo tiempo pensando y trabajando en él y espero poder acometerlo con mucha más amplitud en otra ocasión. Expuse un esbozo de mi trabajo con el título «Nacionalismos, identidad y antropología política» en una conferencia impartida en el Seminario de la UIMP, sede de La Coruña, desarrollado en julio de 1992, con el título general Raíces prehistóricas de la identidad de Europa. 
Sí, en cambio, quiero hacer hincapié en algunas notas muy generales del fenómeno. Considero que éste es fundamentalmente histórico. Esto es, que aparece en una etapa concreta; se genera gracias a una confluencia de factores específicos; se desarrolla de una determinada manera... En suma, se trata de un fenómeno encuadrado en tiempo y espacio delimitados. Por tanto, manifiesto mi acuerdo pleno con las líneas generales de planteamientos como los que en los últimos diez años han mantenido Ernest Gellner y Eric Howsbawn (1988 y 1991). Y, por lo mismo, expreso mi también pleno desacuerdo con quienes, antes y ahora, sostienen que el nacionalismo despierta sustratos dormidos prestos a convertirse, cuando las circunstancias lo permiten, en naciones o incluso en estados. O, peor aún, quienes, un tanto a vuela pluma, vislumbran una especie de revival tribal —algo así como una realidad universal, transcultural, panhumana- detrás de los nacionalismos y sus confrontaciones.

$\mathrm{Ni}$ que decir tiene que ese uso a la ligera de términos como el de tribu implica desconocer la mucha tinta que sobre ellos ha corrido. Término como éste cuyos referentes empíricos carecen de las connotaciones de clara delimitación territorial que muchos creen ver en él cuando se refieren a enfrentamientos por razones territoriales. La fluidez de las fronteras, la difícil delimitación de los grupos étnicos, la fácil incorporación de elementos foráneos gracias a las manipulaciones de las genealogías, hace prácticamente imposible equiparar esos fenómenos con los nacionalismos contemporáneos. Pensemos, sin ir más lejos, que el mapa tribal de Africa (no ya, por supuesto, el mapa de las modernas naciones africanas), dibujado en plena época colonial, responde a los intereses de las metrópolis y está concebido, en cualquier caso, desde mentes cuyo marco vivencial es el estado.

No está de más recordar que, detrás de esa búsqueda de sustratos dormidos, hay toda una invención o construcción romántica y decimonónica que proyecta al pasado las realidades del presente. Así, el historiador Jules Michelet, evocando nada menos que el final de los tiempos carolingios, se preguntaba retóricamente:

“¿Habíamos perecido sin remedio como nación? ¿No había en medio de Francia una fuerza centralizadora que permitiera creer que todos los miembros se volverían a unir y formarían de nuevo un cuerpo?»

Y otro historiador, también francés, Lavisse, rememora a Juana de Arco hablando con Carlos VIII acerca de San Luis y de Carlomagno: "Esta hija del pueblo sabía que Francia existía desde hacía mucho tiempo y que su pasado estaba lleno de grandes recuerdos» (ambos, apud Girardet, 1957: 157; cursivas, mías $)^{7}$. ¿Qué pensar de todo esto cuando se sabe que nación, país o patria eran, todavía a finales del siglo XVIII, términos locales —esto es, de aldea o, a lo más, de comarca o región-? El mismo término patria aparecía definido así, local-

7 Pueden encontrarse ejemplos semejantes en un interesante estudio del fenómeno por parte de Murillo Ferrol (1963). 
mente, en fecha tan tardía como la de 1776, es decir, en vísperas de la Revolución (Hobsbawn, 1991: 99).

Mudables, además, parecen ser los contenidos de esos términos y los sentimientos que evocan en distintos grupos en el correr de los tiempos. Pensemos en nuestras peninsulares tierras. De un reciente estudio histórico sobre los conflictos que generaba la administración de las colonias americanas entre grupos nacionales de nuestro país durante el siglo XVII tomo las siguientes palabras:

"Contrariamente a lo que se pueda creer, el vasco intentaba mostrarse como el más español de los españoles (...) Se creía el vasco la flor y nata de la "nación española"; detentador de una fidelidad a su rey muy por encima de la de un andaluz, un castellano o un extremeño (...) Dentro de la "nación española" convivían otras "naciones" que juntas componían aquélla. El hecho de aplicar la voz de "nación" a los miembros de una comunidad no implica, ni mucho menos, que esos individuos albergasen un sentimiento nacional» (Serrano, 1993: 30-31).

Sin embargo, puede ser vano intento mostrar lo movedizo y cambiable de estos fenómenos. Si las administraciones locales o autonómicas de estas tierras se empeñan en realizar esa proyección hacia el pasado que practicaron los románticos, poco puede hacer el investigador que dependa de subvenciones procedentes de esas fuentes. Como escribe un sociólogo estudioso de la Administración pública, ésta realiza una definición de la realidad que supone una neta demarcación entre «dos mundos diferentes: el mundo de lo que por ser existente es relevante para su consideración (...) y el mundo de lo que por su inexistencia es irrelevante para la Administración» (Beltrán, 1991: 166). Bien entendido que los criterios de existencia e inexistencia no tienen por qué coincidir con los del ciudadano. Es la Administración la que decide lo que es relevante y, por tanto, real o existente (ibid.).

Frente a esa realidad se estrella toda crítica. Amigos arqueólogos me cuentan las dificultades administrativas con las que se topan cuando un yacimiento desborda los límites de una comunidad autónoma. A nosotros nos puede pasar lo mismo, si no nos está pasando ya. El estudio de las identidades autonómicas, con la a veces obsesiva búsqueda de lo específico andaluz, vasco... o lo que sea, roza o cae sin más en el peligro al que vengo refiriéndome. Y entonces sirve de muy poco la sabia advertencia de todo un teórico del fenómeno nacional, cuando aventuraba hace ciento once años, en 1882, la posibilidad de una confederación europea, superadora de los nacionalismos belicosos. Decía Ernest Renan: «Las naciones no son algo eterno. Han tenido un inicio y tendrán un final» (1987: 84). Claro que es posible que lo que provocaran las palabras de Renan fuera no tanto la deseada unidad europea como la temida nación germana.

Vayamos ahora al segundo ejemplo. Tiene que ver con lo que Michel Maffesoli ha denominado el reencantamiento del mundo (1990). Se trata, mucho 
más que en el caso anterior, de una tendencia o una actitud bastante extendida en la investigación antropológica, en nuestro país y fuera de él. Se manifiesta a través de una yo diría que obsesiva y casi exclusiva dedicación a las ocasiones festivas, muchas veces religiosas y algunas otras profanas. Frecuentemente, la lógica preocupación por situar esos hechos en un contexto social hace que se busquen las conexiones que la fiesta, romería o procesión de que se trate tienen con fenómenos de identidad grupal: local, comarcal o de comunidad autonómica. Lo cual viene a jugar el papel de aval de que el antropólogo se ocupa de cuestiones actuales, pero sin abandonar en absoluto la temática más añejamente antropológica.

Tradición — de anteayer, a veces - fundida territorialmente con la demarcación de unidades administrativas. Y con ello ya rozamos esas definiciones de la realidad a que me refería hace un momento. He sido testigo - entre divertido y estupefacto- de cómo algunos responsables de la Administración (estatal, autonómica, provincial) aceptan con naturalidad que el oficio de antropólogo tiene mucho que ver con fiestas, festejos y festividades.

Tal vez, el riesgo que puede correrse es que algún gestor de caudales públicos piense algún día que, ya que las estudiamos, por qué no actuamos también de pregoneros de esas actividades lúdico-religiosas. Actitud, qué duda cabe, encomiable desde la óptica ahorrativa de un buen administrador, pero quizá algo atentatoria contra la dignidad profesional del antropólogo. Probablemente, por eso no venga nada mal que en muchos trabajos antropológicos que abordan estas cuestiones aparezcan con enorme frecuencia los términos rito y ritual. Tal vez, muchas veces no signifiquen nada o muy poca cosa, o es posible que contribuyan a que nuestros saberes y prácticas parezcan bastante más crípticos de lo que ya se supone que son. Pero, en todo caso, pueden aportar algo así como un sello de calidad o denominación de origen y evitar esas lamentables confusiones.

De todos modos, estrategias como éstas son comprensibles. La bondad de los resultados cuando de ellas se derivan investigaciones empíricas es, obviamente, muy dispar. En otra ocasión y a propósito de esto mismo escribí que me preocupaba que el día de mañana algún lector de la etnografía hispana pensara que nuestro hoy era puramente festivo y aproblemático (Luque, 1991). También me preocupa que muchas o bastantes investigaciones de esa especie se apoyen en un sustrato teórico e ideológico afín a ese supuesto reencantamiento del mundo.

Es decir, en ese discurso de Maffesoli que consiste en concebir la sociedad actual, o postmoderna, como simple imagen invertida o especular de la sociedad moderna. La misma expresión reencantamiento no es sino la contraria de la weberiana desencantamiento ${ }^{8}$. Como lo son igualmente estas otras: lo local fren-

${ }^{8}$ Empresa probablemente destinada al fracaso. Como señala Fabian, ya Parsons intentó, sin éxito, "purifying Weber's brillantly condensed analytical categories and type constructs from their historical, temporal substance» (Fabian, 1983: 23). 
te a lo global, el pueblo frente al proletariado, la magia frente a la razón o la masa frente al individuo (Maffesoli, 1990: 66, 70, 88, 164).

$\mathrm{Ni}$ que decir tiene que son los primeros términos de estos pares de oposiciones los que definen, según Maffesoli, nuestro momento histórico. Un momento, hay que apuntar, que se parece demasiado a lo que antecedió a la modernidad, si bien los contenidos son diferentes:

"Podemos imaginar que hoy en día nos hallamos ante una forma de "comunión de los santos". Las mensajerías informáticas, las redes sexuales, las distintas solidaridades y las convocatorias deportivas y musicales son sendos índices de un ethos en formación (...) nuevo Espíritu del Tiempo» (Maffesoli, 1990: 135).

Pero lo de nuevo resulta gratuito si pensamos que en este mundo reencantado

"se sacrifica a "dioses" locales (...) que pueden haber cambiado de nombre desde la antigüedad grecorromana pero cuya carga emblemática sigue siendo idéntica a sí misma» (Maffesoli, 1990: 92; cursivas, mías).

En realidad, no sé qué irrita más de un planteamiento como éste: si lo ficticio de las oposiciones binarias o la fascinación por el retorno de lo mismo. Lo primero suena a puro pulso dialéctico con un manual de modernización sociopolítica de los años sesenta. Supone, además, tomar como dato de realidad lo que es, ante todo, categoría analítica. Ahora bien, la complejidad, que muchos consideran con justicia la marca de nuestra época (en el pensamiento y en la vida), casa mal con esos dualismos simplificadores, que reflejan tan pobremente las realidades sociales antiguas, modernas o postmodernas. En cuanto a lo segundo, no es sino una muestra más de esa dificultad para entender y aceptar la irreversibilidad del tiempo.

Antes de abordar el tercer ejemplo es conveniente una aclaración. Es posible que cierta antropología haya exagerado la singularidad de las culturas y la consiguiente dificultad para entenderlas desde fuera, sin imponerles las categorías, valores, óptica, vivencias en suma, de la cultura de la que el investigador procede. Situación ésta que, sin duda, responde, más que al presente, a la concepción de otra época en el desarrollo de la disciplina. Al margen de que el antropólogo trabaje cada vez más en su propia o semejante sociedad y los problemas sean mucho más sutiles, hay que tener en cuenta que el absoluto aislamiento de sociedades y culturas nunca ha sido más que una premisa teórica sin apenas apoyatura empírica. Además, el planteamiento mismo (fueraldentro) revela a las claras el primado del espacio. En breve, que la comunicación entre mundos culturales distantes y distintos no sea en modo alguno fácil, no quiere decir que sea imposible?

\footnotetext{
9 Véanse las interesantes precisiones al respecto de MacIntyre (1970).
} 
Algunos deben pensar que lo que no plantea, en cambio, ningún problema es el estudio antropológico de otra época de nuestra propia historia. Me refiero a una aportación reciente sobre la imagen del rey en la monarquía de los Austrias (Lisón, 1992).

Voy a detenerme muy poco en esta tercera y última ilustración. El texto aquí habla casi por sí solo. De ella me interesa destacar algunas notas finales de un largo y verbalmente enrevesado discurso. Como se trata de materia propiamente histórica (una época bien delimitada en el tiempo), uno esperaría que el antropólogo no cayera en la seducción de lo inmóvil o permanente. Por desgracia, no es el caso. Tras advertir que no es lo mismo la realeza austríaca, babilónica, del Bali de hace poco o del Egipto de hace mucho, asiria o escandinava..., se diría que nos encaminamos ya a conocer la especificidad de la que se estudia. Pero no. De ahí se nos lleva, primero, a añejos conceptos espaciales como son los de área y subáreas culturales, para abocar, luego, a la más concreta del mundo indoeuropeo, todo ello combinando las «aportaciones históricas de Dumézil» con el «análisis estructural del mismo fenómeno a lo Needham» (Lisón, 1992: 178). De pasada, la renovación, más histórica que estructuralista, de los finales ochenta sobre temas indoeuropeos ha venido a cuestionar seriamente la rigidez y fiabilidad de los esquemas, más estructuralistas que históricos, de Dumézil ${ }^{10}$.

Pues bien, el autor no parece conformarse con esa concreción espacial y sigue avanzando:

«Esta constatación de filiación y pertenencia a una extensa y profunda área cultural, con ser importante y verdadera, presenta un reto intrigante a la reflexión imaginativa del antropólogo: ¿quedan por esta incardinación cultural explicadas así la monarquía y la realeza? En modo alguno; debe seguir inquiriendo y buscando conexiones más primarias y elementales, principios todavía más universales y englobantes que incluyan en este caso concreto a la realeza o más exactamente preparar el tránsito de la realeza de los Austrias a La Realeza, esto es a una concepción metafisica de mayor distribución (...), un modo primario y fundamental de clasificación, un complejo sintético mental, un arquetipo (...). El que entiende la Realeza como adscrita sólo a un tiempo, forma política o persona concreta ha perdido su significado potencial esencial. Mrs. Thatcher rezumaba realeza» (Lisón, 1992: 180 y 181).

Lo único que de verdad comprendo, aunque no comparto, de esta parrafada es el encendido entusiasmo ante la ennoblecida dama británica. Pero no tengo empacho en declarar que no me importa perderme el significado potencial esencial de nada. Tampoco creo mucho en La Realeza ni en cosa alguna

${ }^{10}$ Como ponen de relieve, desde perspectivas muy diferentes, las obras de Renfrew (1988) y de Mallory (1991). 
con mayúsculas. Dudo, además, kantianamente, de muchas metafísicas. Desconfío profundamente de todo lo primario y elemental, algo que me recuerda la inútil búsqueda de átomos que terminan siendo divisibles... Echo de menos, en cambio, un estudio antropológico de la génesis y transformaciones — rituales, si se quiere - del Estado moderno en la España de los Austrias.

De momento, me temo que haya que seguir confiando en el buen quehacer de historiadores y sociólogos. Pienso, por ejemplo, en ese magnífico estudio de Peter Burke sobre la fabricación de Luis XIV de Francia, donde se combinan magistralmente el estudio del ritual de la corte con el de las técnicas de propaganda que preanuncian nuestra época. Burke apela, precisamente, a la estrategia de los antropólogos, especialistas en otras culturas, para hacer inteligibles al hombre de hoy el ritual político de la segunda mitad del siglo XVII, dada la distancia cultural que separa una de otra época (Burke, 1992: 36). Cautela ésta que no debería resultar novedosa para quienes, desde cualquier óptica disciplinar, intenten acercarse a época tan próxima y distante a la vez como la de la sociedad cortesana. Ni que decir tiene que estoy aludiendo a lo que representa el espíritu y la obra concreta de Norbert Elias (Elias, 1982). Historiadores y sociólogos han debido aprender la lección de los antropólogos; en nuestro caso basta que la recordemos.

\title{
EPPUR, SI MUOVE!
}

\begin{abstract}
And yet, and yet... Negar la sucesión temporal, negar el yo, negar el universo astronómico, son desesperaciones aparentes y consuelos secretos. Nuestro destino (a diferencia del infierno de Swedenborg y del infierno de la mitología tibetana) no es espantoso por irreal; es espantoso porque es irreversible y de hierro. El tiempo es la sustancia de que estoy hecho. El tiempo es un río que me arrebata, pero yo soy el rio; es un tigre que me destroza, pero yo soy el tigre; es un fuego que me consume, pero yo soy el fuego. El mundo, desgraciadamente, es real; yo, desgraciadamente, soy Borges.
\end{abstract}

(Borges, 1981: 187)

Las ilustraciones que anteceden no agotan, por supuesto, la panorámica de la investigación antropológica actual de nuestro país. Mi propósito no era tan ambicioso. Algunas desbordan nuestras realidades y nuestra disciplina; por otra parte, como sugería al principio, estoy convencido de que otros tipos de investigación que abordan asuntos de palpitante actualidad no se ven en absoluto libres de problemas de fondo semejantes. En todo caso, espero que los ejemplos a que me he referido hayan puesto suficientemente de relieve las dificultades del antropólogo que no quiere huir a la galaxia de las verdades matemáticas. Nuestro tiempo, cualquier tiempo, nos lanza retos nuevos y diferentes que no podemos ni siquiera afrontar, y mucho menos entender y explicar, si buscamos refugio en la repetición, en el sustrato dormido, en lo universal o en lo inmanente. El estudio de lo actual impone, como nunca tal vez, la necesidad de una 
perspectiva histórica, porque el presente — también como nunca- se hace pasado mucho antes de que podamos asimilarlo.

Verdaderamente, nuestra época nos impone un ritmo tan vertiginoso que convierte en más que problemática la vieja y extendida afición de los antropólogos por lo duradero, por lo que viene del pasado. Augé resalta que ese exceso de acontecimientos, unido al intento de comprender todo el presente, hace difícil otorgar sentido a la historia e incluso al pasado reciente (Augé, 1993: 37). Con carácter más pesimista o más radical, Agustín García Calvo habla de nuestra circunstancia como

«un tiempo vacío y siempre futuro, donde nada pasa, puesto que todo lo que pase ya ha pasado: es Historia en el momento que sucede (...) Y la imagen más perfecta de esa reducción de la vida a historia (...) nos la presenta aquí mismo y cada día la televisión: por el solo hecho de estar encuadrado en la pequeña pantalla, todo lo que sucede está ya sucedido, es en el mismo momento Historia» (García Calvo, 1993: 297).

Otro autor subraya, precisamente, la inautenticidad del mundo que nos rodea, caracterizado por preferir el confort de lo desechable a lo que dura tiempo, o que opta por el cambio superficial en vez de una cierta estabilidad «donde se sedimentan las experiencias y el significado» (Ferraroti, 1990: 91) ${ }^{11}$.

Por desgracia, no podemos elegir nuestro tiempo. «En realidad — dice Gadamer- la historia no nos pertenece, sino que nosotros pertenecemos a ella» (en Muller-Vollner, 1990: 261). Y ese inacabable flujo del tiempo se nos presenta hoy como un calidoscopio cuya enloquecida combinación de piezas - como esa que alucina al periodista de mi cita inicial- no parece anunciar ninguna tendencia ni permitir ningún pronóstico. Son, paradójicamente, las ciencias duras, mucho más que nuestras disciplinas humanísticas, las que insisten hoy tanto en la irreversibilidad del tiempo cuanto en las singularidades de las configuraciones de cada tiempo (Prigogine, 1992 y 1993, passim). Tal vez sea ése uno de los pocos consuelos que nos quedan: que esta época ni nosotros ni nadie va a volver a vivirla jamás.

11 Debo también a este libro el haber llamado mi atención hacia la cita de Borges que encabeza este epígrafe. 


\section{REFERENCIAS BIBLIOGRAFICAS ${ }^{12}$}

Augé, Marc (1993): Los no lugares. Espacios del anonimato. Una antropología de la sobremodernidad, Barcelona: Gedisa.

BeLtrán, Miguel (1991): La realidad social, Madrid: Tecnos.

BORGES, Jorge Luis (1981): Otras inquisiciones, Madrid: Alianza Editorial.

Burke, Peter (1992): The Fabrication of Louis XIV, New Haven and London: Yale University Press.

Burrow, J. W. (1970): Evolution and Society. A Study in Victorian Social Theory, London: Cambridge University Press.

ELIAS, Norbert (1982): La sociedad cortesana, Madrid: FCE.

Fabian, Johannes (1983): Time and the Other. How Anthropology Makes its Object, New York: Columbia University Press.

Ferraroti, Franco (1990): Time, Memory and Society, New York: Greenwood Press.

GADAMER, Hans-Georg (1993): El problema de la conciencia histórica, Madrid: Tecnos.

García Calvo, Agustín (1993): Contra el tiempo, Zamora: Lucina.

Gellmer, Ernest (1988): Naciones y nacionalismos, Madrid: Alianza Editorial.

Girardet, Raoul (1986): Mythes et mythologies politiques, París: Editions du Seuil.

HobSBAWn, Eric A. (1991): Naciones y nacionalismos desde 1780, Barcelona: Editorial Crítica.

IgLesias De UsSel, Julio (1987): «El tiempo en la sociedad contemporánea», en Política y Sociedad. Estudios en homenaje a Francisco Murillo Ferrol, Madrid: CIS/Centro de Estudios Constitucionales, vol. I, pp. 113-133.

LÉVI-STrauss, Calude (1978): «Introduction a l'oeuvre de Marcel Mauss», en Marcel Mauss, Sociologie et Anthropologie, París: Presses Universitaires de France.

Lisón Tolosana, Carmelo (1992): La imagen del Rey (Monarquía, realeza y poder ritual en la Casa de los Austrias), Madrid: Espasa-Calpe.

LUQUE, Enrique (1991): «La invención del otro y la alienación del antropólogo en la etnografía hispánica», en María Cátedra (ed.), Los españoles vistos por los antropólogos, Madrid: Júcar, pp. 69-79.

MacInTYRe, Alasdair (1970): "The Idea of a Social Science», en B. R. Wilson (ed.), Rationality, Oxford: Basil Blackwell, pp. 112-130.

MAFFESOLI, Michel (1990): El tiempo de las tribus, Barcelona: Icaria.

Mallory, J. P. (1991): In Search of the Indo-European. Language, Archeology and Myth, London: Thames and Hudson.

Muller-Vollner, Kurt (ed.) (1990): The Hermeneutics Reader, New York: Continuum.

Murillo Ferrol, Francisco (1963): Estudios de sociología política, Madrid: Tecnos.

NADEL, S. F. (1966): Teoría de la estructura social, Madrid: Guadarrama.

POPper, Karl R. (1972): «La lógica de las ciencias sociales», en ADORNO y otros, La disputa del positivismo en la sociología alemana, Barcelona: Grijalbo, pp. 101-119.

Prigogine, Ilyia (1992 y 1993): «El redescubrimiento del tiempo», Archipiélago (10-11 y 12): 69-92 y 87-96.

Renan, Ernest (1987): ¿Qué es una nación? Cartas a Strauss, Madrid: Alianza Editorial.

Renfrew, Colin (1988): Archeology and Language. The Puzzle of Indo-European Origins, London: Jonathan Cape.

SERRANo MANGAS, Fernando (1993): Vascos y extremeños en el Nuevo Mundo durante el siglo XVII: Un conflicto por el poder, Mérida: Asamblea de Extremadura.

12 Agradezco a María Cátedra y a Alvaro Pazos el haberme proporcionado varias e importantes sugerencias bibliográficas que me han sido muy útiles para elaborar este trabajo. También agradezco a Alvaro, a Miguel Beltrán y a Julio Iglesias la lectura crítica de una primera y más completa versión del trabajo, aunque debo advertir que, de momento, apenas he hecho uso de sus oportunas observaciones. 


\title{
RESUMEN
}

La antropología social ha experimentado un importante crecimiento en nuestro país aproximadamente en los últimos diez años, tanto en ámbitos académicos como en aspectos de investigación relacionados con las administraciones regionales. Sin embargo, esa implantación no va acompañada necesariamente de una reflexión y adaptación teórica a las nuevas circunstancias. En este artículo se examinan críticamente tres ejemplos que muestran los riesgos que implican algunas concepciones que prescinden, teórica y prácticamente, de lo que la historia y la temporalidad suponen.

\begin{abstract}
Social anthropology has undergone a considerable growth in our country in the last decade or so, both in academic settings and in some research themes related to regional administration. Nevertheless this has not necessarily brought a theoretical reconsideration on the new circonstances. In the present paper three examples are critically examined as far as they reflect some of the risks involved in views which, theoretically and in fact, rule out what history and temporality should imply.
\end{abstract}

